\title{
Perioperative smoking cessation programs should be standard-of-care
}

\author{
Susan M. Lee, MAS, MD, FRCPC
}

Received: 19 March 2019/Revised: 24 March 2019/Accepted: 28 March 2019/Published online: 11 April 2019

(c) Canadian Anesthesiologists' Society 2019

\section{To the Editor,}

An et al. ${ }^{1}$ make an excellent case for future research exploring whether perioperative smoking interventions included in a multimodal prehabilitation program are superior to a stand-alone smoking cessation intervention.

There is clear evidence that perioperative smoking cessation interventions such as counselling, educational material, and pharmacotherapy are effective, reduce complications, and improve long-term smoking abstinence. $^{2}$ In addition to examining how smoking cessation interventions can fit into prehabilitation programs, another focus should be exploring why perioperative smoking cessation programs have not yet become standard-of-care and how to inspire action as a matter of quality improvement.

Certainly, anesthesiologists must regard smoking as a modifiable risk factor and advocate for delaying elective surgery to allow sufficient time for the beneficial effects of cessation to take effect. Nevertheless, health providers struggle to prioritize smoking cessation advice and support before surgery. In a study involving two regional hospitals in northern British Columbia, after a Stop Smoking Before Surgery program was introduced, only approximately $50 \%$ of the patients reported that they were advised to quit smoking. ${ }^{3}$ A systematic review of perioperative smoking cessation interventions found lower rates of patient recruitment in randomized-controlled trials (RCTs)

S. M. Lee, MAS, MD, FRCPC ( $ه)$

Department of Anesthesiology, Pharmacology, and

Therapeutics, University of British Columbia, Vancouver, BC,

Canada

e-mail: suze.lee@utoronto.ca compared with observational studies; in the RCTs, there was a lower recruitment rate from preoperative clinics compared with surgical wait lists. ${ }^{4}$ These observations suggest that buy-in from patients to participate in perioperative smoking interventions may be influenced even by the research setting.

Patients expect their healthcare providers to provide advice that best prepares them for surgery. Failure to address perioperative smoking may be interpreted by the patient as tacit approval or lack of importance. In fact, some patients, once informed of the risks of perioperative smoking, express surprise that caregivers do not routinely give smoking cessation advice. ${ }^{3}$ It is imperative that all care providers in the surgical pathway, including anesthesiologists, alert smokers to the benefits of quitting smoking and offer them assistance in doing so.

Several strategies could help to facilitate widespread change. Health authorities should track smoking rates before and after surgery such that quality improvement initiatives can be evaluated. Provinces can extend funding to cover perioperative nicotine replacement therapy or varenicline, as many patients only access nicotine replacement while in hospital and thus miss a key window of preoperative intervention. Further research could examine the effectiveness of "opt-out" vs "opt-in" smoking cessation interventions in the perioperative period, as these have doubled success rates in other settings. ${ }^{5}$

It is time for anesthesiologists to lead the widespread implementation of perioperative smoking cessation interventions during a period when patients are more vulnerable, motivated to quit, and the benefits are profound. 
Conflicts of interest None declared.

Editorial responsibility This submission was handled by Dr. Steven Backman, Associate Editor, Canadian Journal of Anesthesia.

\section{References}

1. An D, Ayob F, Rajaleelan W, Chung F, Wong J. Preoperative smoking cessation as part of surgical prehabilitation. Can J Anesth 2019; 66: 476-9.

2. Thomsen T, Villebro $N$, Mфller AM. Interventions for preoperative smoking cessation. Cochrane Database Syst Rev 2014; 3: CD002294.

3. Bottorff JL, Seaton CL, Viney N, Stolp S, Krueckl S, Holm N. The stop smoking before surgery program: impact on awareness of smoking-related perioperative complications and smoking behavior in Northern Canadian communities. J Prim Care Community Health 2016; 7: 16-23.

4. Song F, Brown TJ, Blyth A, Maskrey V, McNamara I, Donell S. Identifying and recruiting smokers for preoperative smoking cessation-a systematic review of methods reported in published studies. Syst Rev 2015; 4: 157.

5. Campbell KA, Cooper S, Fahy SJ, et al. 'Opt-out' referrals after identifying pregnant smokers using exhaled air carbon monoxide: impact on engagement with smoking cessation support. Tob Control 2017; 26: 300-6.

Publisher's Note Springer Nature remains neutral with regard to jurisdictional claims in published maps and institutional affiliations. 